Acta Poetica 31-1

ENERO-JUNIO

2010 (61-99)

\title{
Rut, migrante ejemplar. El duelo y las políticas simbólicas de la inmigración
}

\author{
Bonnie Honig
}

La autora emplea el Libro de Rut para repensar la política simbólica de la inmigración. Expone y critica dos recientes lecturas de la historia de Rut, la de Cynthia Ozick y la de Julia Kristeva, para luego ofrecer la propia, en la cual invierte las preguntas habituales sobre los inmigrantes: en vez de preguntarse cómo resolver el problema de los inmigrantes, se pregunta qué problemas pueden ellos resolver y cómo las políticas simbólicas de la inmigración despliegan la extranjería en aras de la democracia o la nación. Afirma que tanto Ozick como Kristeva, a pesar de reconocer el valor del extranjero para refundar el régimen al que arriba — para Ozick por el hecho de elegirlo, para Kristeva por su diferencia, que inquieta toda pretensión de soberanía - ignoran la profunda indecidibilidad del inmigrante, quien desestabiliza a dicho régimen (de ahí las repetidas referencias a Rut como "la moabita"), al tiempo que, lo complementa y así ayuda a apuntalarlo (en el caso de Rut, dicho complemento sería su ejemplar virtud). A partir de esta lectura de Rut, la autora propone reconocer la necesidad que tiene todo inmigrante de contar con espacios donde pueda llevar a cabo un duelo real por lo que pierde, así como la necesidad de que un verdadero cosmopolitismo democrático se comprometa con el extranjero en tanto tal, sin exigir que afirme las categorías dominantes del régimen que lo recibe. Finalmente, da ejemplos de espacios donde estas labores de duelo y de vida en conjunto se pueden llevar a cabo, para proponer un cosmopolitismo democrático que se nutra de la indecidibilidad de sus inmigrantes, en vez de sentirse amenazado por ella.

Palabras ClaVE: Rut, inmigración, indecidibilidad, política, psicoanálisis, cosmopolitismo. 
The author reads the Book of Ruth in order to rethink the symbolic politics of immigration. Her own reading of Ruth's story is presented after a critique of two other recent deployments of it, Cynthia Ozick's and Julia Kristeva's, and guided by a reversal of the usual questions about immigrants: instead of asking how we should solve the problem of the foreigner, the author asks "what problems might the foreigner solve for us? And, how do the symbolic politics of immigration redeploy foreignness on behalf of democracy or the nation?". She argues that, although both Ozick and Kristeva acknowledge the power of the foreigner to found anew the regime that receives him (according to Ozick through the act of choosing such a regime, according to Kristeva through his difference, which "worries" the regime's sovereignty), they at the same time ignore the deep undecidability of the immigrant, who both unsettles the regime with his foreignnness (hence the text's repeated references to Ruth as "the Moabite") and helps shore up the regime with his supplement (in Ruth's case this supplement is said to be her exemplary virtue). From this reading of Ruth, the author argues for acknowledging the need of the immigrant of spaces in which he can properly mourn his losses, as well as the need for a real democratic cosmopolitanism to engage the foreigner as such, without asking him to affirm the dominant categories of the receiving regime. She concludes by giving examples of spaces in which such a work of mourning and of living together can take place, in order to propose a democratic cosmopolitanism which is nurtured, and not only threatened, by the undecidability of its immigrants.

KEY wORDS: Ruth, immigration, undecidability, politics, psychoanalysis, cosmopolitanism.

Fecha de recepción: 7 de febrero de 2010

Fecha de aceptación: 14 de abril de 2010 
Bonnie Honig

Northwestern University,

Evanston, Estados Unidos de Norteamérica

\section{Rut, migrante ejemplar. \\ El duelo y las políticas simbólicas de la inmigración ${ }^{1}$}

Traducción del inglés de Daniel Stern

Y nosotros los americanos somos el pueblo peculiar, elegido — los israelitas de hoy.

Herman Melville

Uno de los principales peligros de los que hoy en día Estados Unidos intenta defenderse son los inmigrantes. Y sin embargo, fueron inmigrantes o extranjeros quienes en su momento aportaron parte de la energía que forjó la personalidad de este país. ¿Cómo pensar esta ambivalencia?

Hay quien sugiere que a los inmigrantes de hoy no se les recibe igual y se les percibe como peligro para la unidad de la

${ }^{1}$ Este ensayo está dedicado a mi abuela, Sara Wolloch, quien cumple cien años. Por sus comentarios a borradores previos, agradezco a Seyla Benhabib, Jane Bennet, William Connolly, Richard Flashman, Jill Frank, Marjorie Gaber, Patchen Markell, Pratap Mehta, Martha Minow, Hanna Pitkin, Michael Rogin, Michael Sandel, Tracy Strong, Dennis Thompson, Michael Whinston y, sobre todo, Linda Zerilli. También le debo un agradecimiento a todos los que estuvieron presentes cuando presenté este material en Rutgers, Princeton, Northwestern, Harvard, el Center for Advanced Study in the Behavioral Sciences y el American Bar Foundation. Por su apoyo financiero, agradezco al National Science Foundation, subvención núm. SES-9022102 [N. de la autora]. 
república porque no suelen ser blancos (Ungar, Fresh Blood, 20-21), y algo de verdad hay en ello. Pero también es preciso tener presente que muchas minorías étnicas que hoy se consideran blancas no lo eran cuando sus abuelos llegaron a Estados Unidos: se consideraba negros a inmigrantes irlandeses, del sur de Italia y otros (Ignatiev, How the Irish Became White, 2).

También se dice que el capital humano de los inmigrantes contemporáneos es menor que el de sus predecesores. Los que ahora llegan vienen menos educados y son menos ricos que aquellos que entraron al país antes de que se promulgara la Ley de Reforma y Control de la Inmigración de 1965, más laxa que sus antecesoras (Borjas, Friends or Strangers). Otros subrayan que hay un proceso de selección propia de los inmigrantes: aquellos que completan el viaje suelen ser los miembros más aventurados y capaces de sus comunidades (Portes y Rumbaut, Immigrant America). Existen cifras para apoyar cada lado del debate sobre el capital humano, y por ahora no se vislumbra conclusión alguna. Esto hace pensar en lo inadecuado de los datos recabados, o en la filiación de quienes los recaban o interpretan, pero también en el poder de las políticas simbólicas que aquí operan: ¿dejaría la inmigración de resultar preocupante si pudiera demostrarse categóricamente - como algunos afirman-que, por ejemplo, los inmigrantes dan a la economía más de lo que le quitan, o que en tres generaciones de residencia en Estados Unidos por lo general se han asimilado ya a la cultura dominante, en vez de formar perpetuos enclaves separatistas?

Aunque el argumento racional sobre el costo y los beneficios de los inmigrantes pueda incidir en las políticas migratorias, nunca llegará a decidirlas, pues se trata aquí de identidad tanto como de intereses. ${ }^{2}$ Las constantes politizaciones de la inmigración

\footnotetext{
${ }^{2}$ Como Alan Wolfe dice: "Un marco organizado como hoja de cálculo, en el cual se calculan los beneficios y los riesgos, está demasiado enraizado en el utilitarismo como para hablar de por qué la inmigración tiene tal importancia simbólica para la mayoría de los estadounidenses" ("The Return", 32).
} 
provienen con frecuencia de tensiones en el orden económico o político, pero asimismo son siempre síntomas de una constante ansiedad pública respecto a la identidad y la unidad nacionales. La necesidad (nunca del todo satisfecha) de una identidad nacional enmarca el trato que cada régimen le da a los extranjeros y da pie a historias radicalmente distintas sobre ellos. Los periódicos estadounidenses de hoy en día, por ejemplo, están llenos tanto de reportes ansiosos sobre cómo los extranjeros fragmentan las instituciones de la nación, como de aprobatorias reseñas de memorias de inmigrantes que celebran la "hibridez", la cual designa una identidad no-asimilatoria, compuesta, bilingüe y bicultural. Esta ambivalencia respecto a los extranjeros no solo proviene de la naturaleza de los inmigrantes o de las minorías étnicas en cuestión, sino también de la intención que tiene el régimen de recuperar la extranjería para un proyecto nacional.

La demanda política y cultural de lograr una identidad compartida puede ser la base de la democracia (como pensaba Rousseau) o puede generar demandas de unidad social que, sobre todo en ámbitos multiculturales, entran en tensión con los principios de la democracia liberal. En este ensayo, exploro cómo los extranjeros propician y obstruyen el desarrollo de identidades e instituciones compartidas. Sostengo que la mejor manera de poner hoy en práctica los principios democráticos es a través de un cosmopolitismo democrático y políticamente comprometido en el cual la voluntad de unidad o identidad nacional se vea atenuada y los actores democráticos tengan espacio para buscar, en los registros subnacionales, nacionales e internacionales, afiliaciones políticas, culturales y de otros tipos que no estén fundadas exclusivamente en la identidad. Cada vez más, la práctica democrática excede a los estados que parece presuponer; el demos de la democracia se dispersa.

Me aproximo a estos temas a través del Libro de Rut, un texto que Cynthia Ozick y Julia Kristeva emplean en ciertas reflexiones recientes sobre la identidad, la inmigración, el nacionalis- 
mo y el cosmopolitismo. También desarrollo mi propia versión del ideal del cosmopolitismo a partir de una crítica a la versión de Kristeva y de una nueva lectura del Libro de Rut, la cual emerge del encuentro con las lecturas que proponen Ozick y Kristeva. Considero, al igual que ellas, que el Libro de Rut podría llegar a ser fuente generativa y poderosa de nuevas éticas y disposiciones. Así, mi propósito no es leer el Libro de Rut de una manera contextualista, sino intervenir y participar en despliegues contemporáneos del Libro de Rut como parte de una política simbólica de la inmigración.

Rut

El Libro de Rut empieza con un recuerdo. Años antes, un hombre llamado Elimélej, su esposa Noemí y sus dos hijos parten de Belén huyendo de la hambruna, para llegar a Moab, que según han oído es un lugar próspero. El traslado es controvertido. Elimélej abandona a su comunidad en un momento de penuria y, peor aún, se instala en Moab, enemigo histórico de Israel. Este paso tan prohibido, y la hambruna que lo ocasiona, sugieren que los israelitas se han desviado de sus principios morales fundamentales.

También los moabitas son gente de poca virtud, pero su corrupción no es pasajera. Ellos son los que se niegan a darles agua a los israelitas que atraviesan el desierto para ir de Egipto a la Tierra Prometida, y cuando estos últimos acampan en Bet Peor, mujeres moabitas los incitan a las relaciones ilícitas y a la idolatría. Por todo esto, el Deuteronomio (23:4) prohíbe de manera tajante el matrimonio con moabitas: "Ningún [...] moabita entrará en la congregación del Eterno, hasta la décima generación". ${ }^{3}$

${ }^{3}$ La versión en español de todos los versículos de la Biblia hebrea citados directamente por Honig proviene de la traducción de Moisés Katznelson, publicada por la editorial Sinaí, Tel-Aviv, 1996 [N. del T.]. 
Elimélej muere poco después de haber llegado a Moab. Sus hijos se casan con dos mujeres moabitas, pero también estos hombres mueren al cabo de diez años, dejando tras sí a tres viudas sin hijos, Noemí y sus nueras moabitas, Rut y Orpá. Un buen día, Noemí se entera de que ha terminado la hambruna en Belén, y decide volver a casa. Sus nueras emprenden el viaje con ella, pero en el camino ella les dice: "andad, volveos cada cual a la casa de su madre" en Moab (1:8). Ellas se niegan, Noemí insiste, y finalmente Orpá, llorando, acepta volver a Moab, pero Rut sigue a Noemí. Cuando esta le vuelve a decir que se vaya ("He aquí que tu cuñada ya se ha vuelto a su pueblo y a sus dioses", 1:15), Rut le da una respuesta avasalladora (1:16-17): "dondequiera que tú vayas, iré yo, y dondequiera que hayas de vivir, he de vivir yo. Tu pueblo será mi pueblo, y tu Dios mi Dios. Donde tú mueras, moriré yo, y allí seré sepultada". Noemí no responde, abandona su protesta y Rut sigue el camino con ella.

En Belén, las mujeres de la comunidad reciben a Noemí. Ella les anuncia sus pérdidas y declara que su nombre ha cambiado: ya no se llama Noemí (que significa "placentera"), sino Mara (que significa “amarga”) (1:20). Noemí y Rut establecen un hogar juntas, el cual Rut mantiene recolectando espigas en el campo de un tal Boaz, quien a su vez es pariente de Noemí. Cuando se entera de la singular lealtad de Rut hacia Noemí, Boaz la acoge en su campo y le obsequia aún más grano.

Pero Noemí y Rut desean una protección todavía más segura, y juntas se las ingenian para lograrla. Una noche en el granero, Rut busca (y quizá seduce) a Boaz, donde lo conmina a protegerla mediante el matrimonio y a redimir una parcela de tierra que Elimélej le había legado a Noemí. Boaz le dice que hay otro pariente que lo precede por derecho u obligación de redimir la tierra, pero promete ayudarla. A la mañana siguiente, encuentra a dicho pariente y llama a una reunión con los ancianos del pueblo para resolver el tema de la tierra de Elimélej. 
Cuando el pariente se entera de que Boaz pretende casarse con Rut se desvanece su interés en redimir la tierra, pues sabe que un eventual hijo de Rut y Boaz podría reclamar dicha tierra como herencia, así que le cede su opción/obligación a Boaz. ${ }^{4}$

Finalmente, Boaz y Rut se casan y tienen un hijo, que será criado por Noemí. La comunidad de mujeres celebra, declara al niño hijo y protector de Noemí en su ancianidad, le dedica a Rut el mayor elogio, de valer para Noemí más que siete hijos, y llama al niño Obed. De Rut no volvemos a oír, y desde luego no aparece en la genealogía patrilineal que cierra el Libro de Rut, la cual termina con David, futuro rey de Israel. La débil posición de Rut en el orden israelita se estabiliza mediante un matrimonio y un nacimiento que proporcionan la energía fundadora de un nuevo régimen monárquico. Al mismo tiempo, la migración de Rut parece ser el vehículo de este oportuno cambio de régimen. El Libro de Rut empieza "en los días en que juzgaban los jueces", días de hambruna, infertilidad y corrupción, y cierra con una cosecha abundante y un nuevo hijo que anuncia la próxima monarquía.

Sin embargo, este acontecimiento que funda un régimen no nos aclara en qué lugar queda Rut como inmigrante. ¿Cómo entender su silencio final? ¿Se ha integrado a su nueva sociedad, o ha quedado marginada y varada? Y a un nivel más general, ¿qué conexiones entre inmigración y fundación presupone y consolida este gran cuento corto? ¿Qué pinta una mujer moabita - un extranjero prohibido- en el inicio de la estirpe de David?

\footnotetext{
${ }^{4}$ Los detalles de esta escena suscitan cierta controversia: ¿al pariente se le pide que redima la tierra comprándola, o que redima a Rut casándose con ella? Fewell y Gunn, en Compromising Redemption, resumen dicho debate y proponen la mejor lectura posible de la escena.
} 


\section{Inmigración y fundación}

Para dos recientes lectoras del Libro de Rut - Cynthia Ozick y Julia Kristeva - su protagonista es una migrante ejemplar. Según Ozick, el Libro de Rut habla de la nueva fuerza que aporta una conversión o una asimilación, lo cual concuerda con la lectura tradicional, dominante, del cuento. La conversión de Rut de la idolatría moabita al monoteísmo judaico prueba el valor del Dios judío. La devoción de Rut hacia Noemí habla de su virtud, ejemplo para todos y base del reino de David. Rut, la inmigrante y conversa ejemplar, complementa el orden israelita y lo salva del mal gobierno de los jueces fundando una nueva monarquía soberana.

En cambio, Kristeva considera que Rut desajusta el orden al que ingresa, pues a pesar de que afianza la soberanía israelita también la desgarra en el momento de otredad que personifica como moabita. Mientras que la Rut de Ozick completa el orden israelita, la Rut de Kristeva hace imposible que dicho orden alcance cualquier tipo de completud. Y este, piensa Kristeva, es el gran servicio de Rut a los israelitas: rompe con sus fantasías identitarias y los abre a la diferencia y la otredad. Pero la Rut de Kristeva no solo desajusta el orden al que llega, también adopta sus costumbres y rituales, y se esfuerza por encajar. De acuerdo con Kristeva, eso hace de Rut un modelo valioso para aquellos inmigrantes musulmanes que hoy se resisten a ser absorbidos por los regímenes que los reciben. ${ }^{5}$

\footnotetext{
${ }^{5}$ Hay quien duda que el Libro de Rut pueda dar cuenta de la política migratoria por el hecho de que cuenta la historia de una sola migrante, mientras que hoy en día hablamos de masas de migrantes. Mi opinión es que el texto logra dramatizar tan bien temas migratorios de todas las épocas gracias en parte a su uso de la personificación. Además, la historia de Rut estableció conexiones con la política migratoria mucho antes de mi propio análisis. Marjorie Garber (comunicación personal) recuerda haber hecho el papel de Rut a fines de la década de los 40 en una serie de eventos patrocinados por Hadassah para recaudar fondos para los refugiados judíos que viajaban a Palestina después de la guerra. Ya que Kristeva emplea el velo para subrayar la resistencia de los inmigrantes musulmanes, es interesante notar que Gar-
} 
Cada una de las particulares relecturas que hacen Ozick y Kristeva del Libro de Rut combina dos de las respuestas más comunes y perdurables que tenemos hacia los inmigrantes. Una es la de valorarlos por lo que "ellos" nos aportan a "nosotros" —diversidad, energía, talento, industria, nuevos sabores y recetas, además de una renovada apreciación de nuestro propio régimen, con virtudes como para atraer inmigrantes - y otra la de temerle por lo que nos harán — consumir nuestra asistencia social, diluir nuestro patrimonio cultural, fragmentar nuestra política o socavar nuestra cultura democrática o cosmopolita. Ambas respuestas valoran al inmigrante en términos de lo que hará por nosotros (o a nosotros) como nación.

Para la primera respuesta, acogedora, la inmigración constituye una ocasión para que los ciudadanos (quizá hastiados) vivan de nuevo la admiración ante el momento fundante, en el cual la verdad o el poder de su régimen fuesen revelados o promulgados al mundo entero. Cabe recordar que Moab es (como dijo el presidente Clinton en un discurso pronunciado en Medio Oriente en otoño de 1994) "la tierra donde murió Moisés y nació Rut", y Rut el vehículo gracias al cual la Ley adquiere nueva vida generaciones después de la muerte del legislador, Moisés.

La inmigración y conversión de Rut reeditan el contrato social de Sinaí y permiten a los israelitas experimentar nuevamente su propia conversión inicial, su fe o admiración originales ante la Ley. El que Rut elija a los israelitas vuelve a marcarlos como el Pueblo Elegido, es decir, un pueblo digno de ser elegido. Según esta lógica, ser elegidos por el inmigrante nos permite valorar lo que somos (un ejemplo del placer y la fuerza causados por la vivencia de ser elegidos es la foto de nuevos ciudadanos tomando el juramento que publica periódicamente

ber, en el papel de Rut, llevaba un velo para subrayar la identidad (de refugiada) europea de su personaje. 
el New York Times. Dicho placer es protegido aún mejor por el hecho de que Estados Unidos no mantiene ninguna estadística oficial sobre la remigración o emigración). ${ }^{6}$

La segunda respuesta a la inmigración, desconfiada, también sugiere una nueva experiencia de la fundación. Aquí, sin embargo, domina el impulso de afianzar la seguridad del régimen incluyendo a ciertas personas, valores y modos de vida y excluyendo otros, ${ }^{7}$ con lo que ser elegidos por el inmigrante más bien supone un peligro para nuestra conciencia de nosotros mismos. Si aunamos la narrativa de la migración de Rut a la decisión de Orpá de no emigrar, el Libro de Rut se lee como intento de reforzar la identidad israelita sin por ello ponerla en peligro. Como bien dice Ozick, la contraposición entre Rut y Orpá subraya lo extraordinario que es el desplazamiento que lleva a cabo la primera ("Ruth", 221). Pero dicha contraposición tiene además otro efecto: nos hace ver que la migración de Rut a Belén no implica que Israel sea ahora una comunidad sin fronteras, abierta a cualquier extranjero, aun al moabita idólatra. Israel solo abre sus puertas al moabita excepcionalmente virtuoso: a Rut, no a Orpá.

Así, Rut y Orpá tomadas en conjunto personifican la admiración $y$ el miedo, la oportunidad $y$ la amenaza, las sensaciones de complementación $y$ de fragmentación que provoca el inmigrante en los órdenes que lo absorben o lo excluyen (¿acaso Orpá no resulta amenazante? Los intérpretes tradicionales dan voz a este miedo cuando afirman que Goliat desciende de ella). Podría pensarse que estos impulsos, personificados por los bien diferenciados personajes de Rut y Orpá, se adhieren a objetos distintos, por ejemplo el inmigrante malo y el bueno. Pero,

${ }^{6}$ Se estima que 195,000 residentes de Estados Unidos emigran anualmente (Labovitz, "Immigration"). Yo hablo en detalle de las funciones simbólicas de la icónica fotografía del nuevo ciudadano (Honig, Democracy).

${ }^{7}$ Toni Morrison apunta de manera aguda a la dimensión de exclusión del efecto (re)fundacional de la inmigración estadounidense en relación con los negros de este país ("On the Backs of Blacks"). 
¿qué pasa si vemos en Orpá una parte de Rut, una personificación de aquella parte de Rut que, aún en Belén, no puede evitar seguir siendo moabita? En tal caso la historia quizá ilustraría la profunda y persistente ambivalencia que suele sentir cualquier régimen — aun siendo democrático — ante el extranjero que vive en su seno.

La radical extranjería de Rut es realmente lo que posibilita su fabulosa conversión: esta solo es notable en tanto que Rut es moabita. Es precisamente su extranjería la que la capacita para mostrar que los israelitas son dignos de ser elegidos y para renovar su identidad de Pueblo Elegido. Pero la extranjería de Rut también la vuelve amenazante para el régimen que de otro modo simplemente reforzaría. No hay modo de obviarlo: ¡una moabita se ha instalado en Belén!

En pocas palabras, Rut encarna la profunda indecidibilidad de la inmigrante, cuya extranjería complementa a la vez que amenaza el régimen que la recibe. Kristeva busca en el Libro de Rut una alternativa, una manera de recibir la extranjería que nos parece tan amenazante, pero en última instancia su cosmopolitismo sucumbe a un singular discurso de nación elegida. También yo acudo al Libro de Rut en busca de alternativas.

\section{La Rut de Ozick: ¿Conversa o migrante?}

La lectura que hace Ozick (1994) del Libro de Rut se nutre de las interpretaciones rabínicas tradicionales, pero también se aleja de ellas de manera significativa: "En cuanto al resto de mi viaje por el texto, pretendo continuar más o menos sin ellos [los rabinos]" ("Ruth", 219-220). Mientras que anteriores intérpretes solo percibían a Orpá en términos de su poca favorable comparación con Rut, Ozick se detiene a considerarla en sí misma. "Interroguemos el relato, imaginemos una pausa y démosle entrada a la normalidad: que nadie pase por alto a la joven y aba- 
tida Orpá” (221). El fracaso de Orpá (en comparación con Rut) al emigrar a Belén en aras de Noemí y del monoteísmo no es lo único que hace de ella un personaje notorio. Orpá se distingue por lo admirable de su propia acción: se casa con un israelita en Moab (desde luego una decisión impopular) y llega a amar a Noemí. Puede que Orpá no haya superado las pruebas del monoteísmo y la emigración, pero ciertamente era una mujer con un "corazón abierto" (224) que pudo transcender las barreras del "estrecho" prejuicio convencional (222).

La Orpá de Ozick es especial, pero en última instancia, ante la encrucijada que supone la decisión de emigrar o no, se revela el verdadero principio de su personalidad: ella representa la "normalidad", no la "singularidad" (220). Sus deseos son mundanos, su imaginación no vuela. Volver a casa de su madre es volver a sus ídolos. A Orpá "nunca jamás habrá que culparla por" su elección, afirma Ozick, pero aun así sugiere que la historia se ha encargado de juzgarla ("Su marca es borrada de la historia, no existe ningún Libro de Orpá", 221). Ozick se detiene a reflexionar en Orpá y se resiste así al juicio de la historia, pero también lo consolida, pues para ella la desaparición de Moab y de Orpá del acontecer histórico es merecida y no fortuita, y la decisión de Orpá es ordinaria e inmadura en comparación con la de Rut, que resulta "visionaria" (224). "Rut abandona Moab para dejar atrás sus ideas infantiles” (227).

La contraposición que plantea Ozick entre Rut y Orpá, aunque suavizada por su pausa apreciativa, ejemplifica su distinción entre lo normal y lo singular. Pero también tiene otro resultado: deshace la indecidibilidad de la inmigrante que apoya, pero también amenaza con socavar el orden que depende de ella y peligra por ella. Ozick ubica a Rut, la inmigrante, en un lugar desde el que puede reforzar el orden israelita sin al mismo tiempo amenazar con corromperlo. Dicha amenaza, y el espectro de la extranjería inconvertible, son proyectados hacia Orpá, cuya incapacidad para emigrar simboliza la incapacidad 
para convertirse (y viceversa). Si al quedarse en casa Orpá se queda con sus dioses, entonces al dejar su casa Rut deja a sus dioses. La contraposición elimina cualquier duda acerca de la conversión de Rut. Su presencia en Belén no es un peligro. Ciertamente está con "nosotros".

En otro momento de su ensayo, Ozick consolida aún más el carácter no amenazante de la reforzadora inmigración de Rut. En una bella observación sobre Noemí, comenta que su instrucción a Rut de seguir a Orpá y regresar a "su pueblo y sus dioses" muestra que Noemí es "una especie de pluralista" avant la lettre (223). Noemí, dice Ozick, no es celota: Orpá tiene sus dioses, Noemí los suyos, y esta lo sabe y lo acepta. Pero dicha aceptación de la idolatría moabita depende del hecho de que suceda en Moab. Es decir, su pluralismo es territorial. Cuando Noemí dice que Orpá ha vuelto a su pueblo y sus dioses, manda el mensaje (que Rut ciertamente capta) de que no es posible ir a su pueblo, Belén, con dioses moabitas. En el pluralismo de Noemí, los pueblos y sus dioses van ligados y están situados en el territorio que les corresponde. Tiene razón Ozick al decir que este pluralismo es valioso en comparación a las formas de imperialismo o fanatismo que no toleran diferencia alguna sobre la faz de la tierra. Sus límites, sin embargo, se hacen patentes en relación con las formas de pluralismo que exigen tolerar las diferencias que habitan en nuestro seno, en nuestros barrios, en la casa de al lado o dentro de la nuestra.

Ozick, entonces, coloca a Rut y a Orpá como personificaciones de la singularidad y la normalidad, y también territorializa la diferencia cultural. Todo esto establece una distancia segura entre las hermanas. Esta distancia, a su vez, opera (de manera intencional o no) para permitir que Rut sea vehículo del reforzamiento que busca Ozick sin que al mismo tiempo amenace la identidad israelita. La Rut de Ozick es capaz de complementar el orden israelita sin diluirlo o corromperlo precisamente porque la indecidible figura del inmigrante (en este caso moabita), 
tan necesaria para la renovación de la comunidad como peligrosa para la misma, ha sido escindida en dos partes: Orpá - la moabita práctica, material, quien se queda en "casa de su madre" con sus ídolos - es la figura del Otro cuya ausencia mantiene seguras las fronteras y la identidad de la comunidad, mientras que Rut - leal, entregada a Noemí, partícipe de aquella imaginación madura y abstracta que es necesaria para serle fiel al Dios único e invisible - refuerza las fronteras del orden a través de su conversión. Este proceso de escisión protege el orden israelita de la corrupción moabita, al mismo tiempo que le permite beneficiarse del complemento que es la inmigración de Rut. En resumen, Ozick, asombrada ante el gran complemento que es la reforzadora virtud de Rut, pasa por alto la indecidibilidad de la inmigrante, así como la persistente extranjería de la misma.

El deslinde entre Rut y Orpá que Ozick lleva a cabo proviene de dos interpretaciones cuestionables: primero, que el único objeto de la elección de Rut fue el monoteísmo y, segundo, que fue su excepcional virtud la que le permitió asimilarse fácilmente al orden israelita, el cual a su vez se vio solo mejorado (y no al mismo tiempo amenazado) por ella. La lectura de Ozick, en sus propias palabras, es "irregular y selectiva, un punto aquí, un punto allá” (219), y produce una nueva versión de la historia antes que una interpretación. Lejos de pretender ser un análisis exhaustivo, busca más bien darle nueva vida a este texto antiguo, y desplegarlo para un propósito específico e inspirador.

\footnotetext{
${ }^{8}$ En términos psicoanalíticos, el (excesivo) apego de Orpá a su madre (patria), representado por la frase "casa de su madre" (expresión inusual en la Biblia), le impide como a Antígona (quien se aferraba a Polinices, sitio desplazado de su anhelo por Yocasta, su madre; Irigaray, Speculum of the Other Woman) ingresar a la Ley (paternal o monoteísta), reino de lo Simbólico. Luce Irigaray, animada por una sensibilidad más trágica que la de Ozick, encuentra un lugar subterráneo para Antígona, quien eternamente desajusta el orden dominante. Ozick se detiene por un momento a reflexionar en Orpá, pero no ve en ella una fuente de disonancia eterna o — siguiendo a Irigaray en su apropiación del término hegeliano — de ironía.
} 
Sin embargo, a mí me interesa rastrear las múltiples posibilidades que este texto presenta, pero que la lectura de Ozick oculta, pues dicha labor ilustrará la complejidad de las políticas simbólicas de la inmigración.

Centrándose en las famosas palabras que Rut le dirige a Noemí, Ozick dice que Rut no solo actuó movida por un impresionante amor hacia Noemí, sino también por una profunda fe monoteísta. ¿Cómo explicar aquellas palabras de Rut, "tu dios [será] mi dios", sino desde la fe? ¿Cómo explicar su traslado a Belén? "Todo lo socialmente racional apunta a que Rut se quede en su país" (225). Pero las racionalidades sociales de la situación no están nada claras. No puede haber sido fácil regresar a Moab como la viuda sin hijos de un israelita. Contra Ozick, también la decisión de Orpá tuvo su dosis de valentía. ${ }^{9}$

¿Era la fe la única motivación de Rut? A partir de la instrucción que recibe ("He aquí que tu cuñada ya se ha vuelto a su pueblo y a sus dioses"), Rut puede inferir que a Noemí le preocupa que no pueda ser aceptada ni asimilada en Belén. No te preocupes, responde Rut. Quizá aún no conozco las costumbres, pero te seguiré a donde vayas, viviré donde vivas, tu pueblo será mi pueblo y tu dios será mi dios. ¿Se trata de una conversión ingenua? No necesariamente. Para empezar, el texto mismo no establece con claridad que se trate siquiera de una conversión. Quizá aquí Rut tan solo tranquiliza a Noemí - como tantos otros inmigrantes antes y desde entonces han hecho con quienes los reciben o patrocinan-, asegurándole que no le va a causar problemas. Puede ser que la fe también

\footnotetext{
${ }^{9}$ Ozick encubre las dificultades de dicho retorno, pues menciona la exogamia de Orpá pero a continuación asume que la vida de Orpá en Moab será fácil: "pronto se casará con un moabita y tendrá un hijo moabita" (224). Fewell y Gunn aprecian mucho mejor la situación: “¿Qué oportunidades tiene Rut en Moab? ¿Quién querrá casarse con una viuda sin hijos y, más aún, que vivió con un extranjero? ¿Acaso la llamarían 'amante de israelitas', que se coloca por encima de su propia gente?... A fin de cuentas, nos hemos de preguntar qué resulta más valiente, si quedarse o irse" (Compromising Redemption, 97-98). Cfr. Kaplan, "The Noah Syndrome”, 167.
} 
incidiera en la decisión de Rut, pero el texto no nos da ninguna razón para pensar que fuese determinante. Lo más probable es que los motivos de Rut fuesen muchos y complejos, lo cual se hace patente cuando consideramos que Orpá personifica una dimensión del imposible conflicto de Rut. ${ }^{10}$

Ozick, cuya intención es recuperar la potencialmente turbadora migración de Rut para un proyecto nacional, lee el Libro de Rut como una fábula de asimilación reforzadora y pasa por alto las señales de que la presencia de Rut dentro del orden israelita nunca fue tan solo un apoyo, sino también, y al mismo tiempo, una amenaza. Allí donde Ozick percibe virtud, conversión y asimilación, el texto del Libro de Rut también sugiere complicación, particularismo recalcitrante y prejuicio. Rut no solamente refuerza el orden al que ingresa, también lo contamina y lo perturba. Varias veces el Libro de Rut se refiere a ella como "Rut, la moabita" (1:22, 2:2, 2:6, 2:21, 4:5, 4:9), sugiriendo que ella, en cierto sentido, sigue siendo moabita, prohibida, ciertamente notada y quizá despreciada por su cultura adoptada, aun cuando dicha cultura también la celebre por la virtud que le aporta.

Además (de nuevo contra Ozick), Rut no solo es un personaje virtuoso, sino también transgresor. Según ciertos comentaristas, ella se atreve a seducir a Boaz en el granero (Kates, "Women at the Center", 194-195). La seducción, aunque conjurada por Noemí, es compatible con la identidad moabita de Rut, pues es precisamente por miembros de dicho pueblo que

\footnotetext{
${ }^{10}$ Jack M. Sasson apunta al uso de la personificación en otras partes del Libro de Rut: "Un dispositivo didáctico al que recurren con frecuencia los escritores bíblicos es el de limitar el espectro de decisiones a dos alternativas, sólo una de las cuales será la correcta. Un obvio ejemplo de dicho concepto es la creación de dos hermanos, de los cuales sólo a uno le irá bien. Mahlon se casa con Rut: le irá bien" (a través de la posteridad que es Obed) (Ruth, 16-17). Otros ejemplos bíblicos que Sasson menciona son Caín y Abel, Jacob y Esaú, Ismael e Isaac, todos ellos hombres. ¿Por qué Sasson no incluye a Rut y a Orpá en su lista? Quizá a causa de que supone, a modo de Propp, que Orpá es un personaje marginal, no central a la historia y que no amerita una mayor atención interpretativa.
} 
los israelitas temían ser seducidos. Para Ozick, esta escena (en la cual Rut a la mitad de la noche se acuesta al lado de Boaz y le descubre los "pies") ilustra "una ternura paternal, no erótica - aunque una escena como ésta bien podría, en otro cuento, estar cargada de erotismo" (229-230). Pero el texto, lejos de darle la razón a Ozick, ${ }^{11}$ deja abierta la pregunta de qué sucedió aquella noche. ${ }^{12}$

Finalmente, ¿por qué Rut no cría a Obed? ¿Por qué es reemplazada por Noemí? Un comentarista afirma que el deseo de procrear nunca fue de Rut, sino de Noemí (Reimer, "Her Mother's House", 105). Otra posibilidad, quizá paralela a esta, surge cuando consideramos la condición de Rut de inmigrante indecidible y potencialmente peligrosa: quizá Noemí se hace cargo de Obed para inculcarle la tradición de los israelitas porque su madre moabita no sería capaz de —o no sería alguien a

${ }^{11}$ La afirmación de Ozick recuerda a aquella de Hegel de que la relación entre hermano y hermana, que ejemplifican Polinices y Antígona, no es erótica. Como dice Jacques Derrida, la afirmación resulta asombrosa si pensamos en el origen incestuoso de este par: "Los padres de Antígona no son cualquier par de padres" (Glas, 165).

${ }^{12}$ El término hebreo que se emplea aquí para decir "pies" es un juego de palabras que remite a los genitales. Sasson (Ruth) propone una bella lectura de la escena en la cual se dice que Boaz confunde a Rut con "Lilit". Una lilit es una mujer/espíritu demoníaca a quien se considera responsable de las emisiones nocturnas y la impotencia del hombre. "Al despertar, Boaz discierne la figura de una mujer. Bajo la impresión de que es una lilit, tiembla de miedo. El narrador juega con la idea de que Rut resultará igual de agresiva en su demanda por ser aceptada como pareja. En este caso, pronto se nos hará saber (si no es que lo sabemos ya) que las cosas saldrán bien para todos los involucrados" (Derrida, Glas, 78).

El "juego" de esta escena descansa en que Boaz confunde a Rut con una lilit. Lo que Sasson no menciona es que el error está sobredeterminado tanto por el sexogénero de Rut como por su identidad moabita. Las mujeres moabitas eran temidas por los israelitas, quienes las consideraban especialistas en la tentación y la seducción. Esta escena, entonces, es mucho más (o menos) que un juego. Le permite a Boaz experimentar sus peores miedos acerca de Rut: que, a pesar de su conversión / inmigración, ella es una verdadera moabita, portadora de un deseo que no respeta los límites de la subjetividad israelita masculina. Boaz experimenta dichos miedos precisamente en el momento en que confunde a Rut (a quien ya desea), porque en ese momento se protege desplazándolos hacia una lilit. 
quien se le pudiera confiar- dicha tarea. En tanto inmigrante y en tanto reeditora del contrato social del Sinaí, Rut tiene el poder de ensanchar la capacidad del orden para sentir admiración y fe. En tanto inmigrante, también tiene el poder de desajustar, diluir y quizá fragmentar la sensación de identidad de la comunidad. El que las mujeres celebren a Rut muestra cómo la comunidad aprecia lo primero; el que Obed sea transferido de Rut, quien como moabita no resulta apta para criarlo, a Noemí, muestra cómo la comunidad teme lo segundo. ${ }^{13}$

Estas complicaciones no emergen en la lectura de Ozick porque para ella la indecidible figura del inmigrante está dividida en dos: la que complementa el orden (Rut) y la que lo podría diluir o corromper (Orpá). Ozick lo ve así porque desea que Rut cumpla una función parecida a la del legislador en el Contrato social de Rousseau, cuya combinación de extranjería (viene de fuera) y virtud ejemplar lo faculta para lograr que un orden descarriado recuerde y retome sus principios originales. Rousseau soluciona el problema de la peligrosa indecidibilidad del extranjero proponiendo que se marche tan pronto como haya completado su labor regenerativa (la constitución del régimen no contempla el cargo de legislador, libro II, cap. 7). La pretendida solución de Ozick es la de muchas democracias multiculturales de Occidente: se trata de que el extranjero/extraño que resulta benéfico (o aquella parte del mismo que resulta benéfica) se asimile, y de que el extranjero que resulta peligroso (o su parte correspondiente) se vaya o se quede en su lugar de origen.

La partida de Orpá a Moab no es invención de Ozick, el texto mismo la narra. Pero el texto no nos dice cómo posicionarnos

\footnotetext{
${ }^{13}$ Recuerdo aquí la no tan análoga historia de los "habitantes pelasgos de Lemnos, quienes se llevaron consigo a mujeres atenienses de Brauron y tuvieron hijos con ellas. Cuando sus madres los criaron como atenienses, los padres se asustaron y mataron tanto a las madres como a los hijos. A partir de estos dos sucesos, la palabra 'Lemnion' se asoció con cualquier cosa mala” (Heródoto, Historias VI, 6, 138, apud Hurst-Warhaft, Dangerous Voices, 211, n. 54).
} 
ante la desaparición de Orpá, si desde el duelo, el lamento, la resistencia o la aceptación. El texto tampoco nos indica cómo concebir la relación entre Rut y Orpá. Podemos enfatizar sus puntos en común y buscar sus conexiones, o bien resaltar la distancia entre ellas. Quizá con el fin de lograr una lectura conclusiva y obtener el máximo beneficio de Rut como complemento, Ozick elige lo segundo, domesticando la absorción de Rut y ocultando aquellas diferencias al estilo de Orpá que (al menos según el propio texto) aún inciden en la persona de Rut.

\section{La Rut de Kristeva, inmigrante ideal}

En su lectura del Libro de Rut como un posible modelo alternativo del mito fundante, ${ }^{14}$ Kristeva intenta (re)capturar la indecidibilidad del inmigrante. Hace notar que Rut, "la externa, la extranjera, la excluida" funda un linaje monárquico que ya desde su inicio está resquebrajado por la diferencia (Extranjeros para nosotros mismos, 93). El quiebre es generativo: "Si David también es Rut, si el rey es también un moabita, la tranquilidad nunca será su patrimonio, sino una búsqueda permanente para la acogida y la superación del otro en sí mismo" (94).

Sin embargo, no encontramos rastro alguno de esta relación idealizada ("receptora") con el otro en el lamento de David (citado por Kristeva) cuando exclama: “¿Cuánto tiempo me seguirán hablando airadamente diciéndome: acaso no procede de una rama indigna? ¿No es descendiente de Rut la moabita?”, ni tampoco en su deseo (también citado por Kristeva) de deshacerse de su ascendencia moabita para que la gente lo venere

${ }^{14}$ Basándose en el amor de Rut por Noemí, Kristeva habla de la pasión entre mujeres que está al inicio del linaje de David, la cual contradice los supuestos estructuralistas sobre el intercambio homosocial de mujeres por parte de los hombres como función constitutiva de un orden. Cabría agregar que el intercambio que en este texto constituye un orden es el de un hombre (Obed) que pasa de una mujer (Rut) a otra (Noemí). 
como se merece (93). David fue más celoso de lo que sugiere Kristeva en su trato con los Otros, sin duda superando a Saúl en la voluntad de destruir a sus enemigos. Posteriores intérpretes rabínicos imaginan a David quejándose de que se le identifique con Rut porque piensa (y ciertamente dichos intérpretes piensan) que el fundamento de su régimen resultaría más estable y más seguro sin ella. Sin embargo, David no solo necesita a Rut para "inquietar" su soberanía, como lo expresa Kristeva (93), sino también para complementar sus propias y bien conocidas deficiencias con la historia de la excepcional virtud de aquella, y para apuntalar el esfuerzo de extender su influencia a Moab.

Kristeva argumenta que Rut le ofrece al régimen precisamente su extranjería y su capacidad de inquietar a la soberanía israelita. Pero dicho argumento ignora el hecho de que para los israelitas, al igual que para Ozick, Rut es virtuosa a pesar de su extranjería, o independientemente de ella. Sus ofrendas al régimen son la fe y el carácter ejemplares de ella, manifestados en la voluntad de abandonar Moab por Noemí y de convertirse al monoteísmo. La extranjería de Rut, en sí misma, no ofrece nada.

Kristeva, sin embargo, acierta al percibir cierta promesa en la acogida judaica de Rut y en los diversos requerimientos bíblicos de que Israel sea hospitalario con el extraño o el extranjero (83-84). Pero habla de Rut sin tomar en cuenta a Orpá (a quien apenas menciona), por lo que la Rut de Kristeva fácilmente se convierte (como la de Ozick) en una figura virtuosa por su voluntad de convertirse al monoteísmo israelita y dejar atrás todas las diferencias verdaderamente disruptivas. Sin Orpá y todo lo que representa (por ejemplo, la pertinacia de la diferencia, la nostalgia del inmigrante por su tierra de origen, la prohibición contra los moabitas), Kristeva pierde de vista la indecidibilidad del inmigrante.

Es relevante la ausencia de Orpá en el relato de Kristeva. Esta parece confiar en que el poder ético de historias sobre extraños logrará desplazarnos de nuestra insistencia en la propia 
identidad nacional o étnica. Sin embargo, su propia aceptación de la extranjería acaba dependiendo de la voluntad del extraño de afirmar la existencia y el valor del orden que complementa y perturba. Si Rut, para Kristeva tanto como para Ozick, es la inmigrante ejemplar, es por su voluntad de jurar fidelidad a Noemí, su pueblo y su dios. Y de hecho el cosmopolitismo de Kristeva depende de parecidos juramentos de fidelidad por parte de ciudadanos e inmigrantes franceses por igual (Nations without Nationalism, 63).

\section{Las Orpás de Kristeva: cosmopolitismo sin extranjería}

En Nations without Nationalism, Kristeva vuelve a Rut, la conversa que atraviesa fronteras, para delinear un cosmopolitismo dirigido tanto contra los nacionalistas franceses y los inmigrantes recientes de Francia, como contra los habitantes y ciudadanos magrebíes que "van a la escuela con el velo musulmán" (36). Estos inmigrantes comparten con Rut la voluntad de abandonar sus lugares de origen, pero se asemejan a Orpá por su apego a la cultura particular de su país natal (Extranjeros para nosotros mismos, 194). ¿Acaso no hay nada francés a lo que puedan ser leales? (Nations without Nationalism, 60).

El persistente apego de numerosos inmigrantes argelinos a su cultura y su tierra natal, y la opción desde 1963 de ser ciudadanos de una Argelia independiente, llevó a muchos de ellos a rechazar la ciudadanía francesa o a tomarla en términos puramente instrumentales. Como respuesta, la derecha francesa ha exigido en los últimos diez años mayores controles sobre la inmigración y que la ciudadanía sea otorgada solamente a quien pruebe tener un vínculo afectivo con Francia. La izquierda, por su parte, se opone a los esfuerzos por controlar la inmigración y por inscribir la ciudadanía como práctica afectiva (Brubaker, 
Citizenship and Nationhood, 138-164; Hollifield, Immigrants, Markets and States, caps. 6-7).

Kristeva, quien argumenta que la primera respuesta es demasiado "nacionalista" y la segunda demasiado "volcada hacia el mundo" (pues la izquierda estaría demasiado dispuesta a "vender los valores de la nación francesa", Nations without $\mathrm{Na}$ tionalism, 37), busca entonces un punto medio y propone un cosmopolitismo distintivamente francés, para el cual la nación sigue siendo un factor importante aunque ya no exhaustivo de identidad, centrada no en el Volk sino en el pacto (40). Kristeva resignifica a la nación, que pasa de ser un destino final de afiliación a un objeto transicional, término psicoanalítico que se refiere a aquel objeto, tal como una cobija favorita o un peluche, que el niño emplea para lograr separarse de la madre (patria) y eventualmente, al menos en teoría, ingresar a una existencia independiente, libre de cobijas/posnacional. Kristeva, quien agudamente resquebraja la división entre izquierda y derecha, propone un cosmopolitismo enraizado y afectivo, aunque finalmente apegado a un objeto no nacional, pero sí transnacional.

El cosmopolitismo de Kristeva afianza y es afianzado por relaciones afectivas a una serie de "grupos" —individuo, familia, patria, Europa y Humanidad - en las cuales cada grupo opera como objeto transicional del siguiente (41). Al colocarlos en una trayectoria de transiciones progresiva, secuencial, Kristeva evita los posibles conflictos entre dichos grupos. También evita los problemas de una afiliación específicamente francesa empleando el término abstracto "patria" para referirse a ese grupo. Pero su llamado a identificarse con Europa coloca a sujetos franceses y magrebíes en posiciones asimétricas respecto a su cosmopolitismo (Moruzzi, "A Problem with Headscarves", 665). Y puesto que (como ella afirma repetidamente) es específicamenteporvíadeMontesquieuquedichocosmopolitismo"[se]abre paso en Francia" (Nations without Nationalism, 38), este desem- 
boca en una identidad singularmente francesa, aun cuando afirma superarla o trascenderla. Dice Kristeva que "una identidad no puede ir más allá de sí misma sin antes haberse afirmado de manera satisfactoria" (59), pero este generoso reconocimiento de la necesidad de afirmar la identidad antes de superarla no se extiende a las comunidades inmigrantes de Francia.

Esta paradoja, que plantea que el cosmopolitismo se alcanza a partir de las culturas particulares y heterogéneas (y nacionales) que nos determinan es, desde luego, insoluble. Pero Kristeva, lejos de explorar la paradoja, prefiere hacer a un lado la heterogeneidad de Francia para adherirse a una corriente específica de la Ilustración francesa. Acierta al decir que debemos "llevar a cabo una crítica de la tradición nacional sin malvender sus bondades", pero su descripción del cosmopolitismo francés en última instancia protege de la crítica y del compromiso crítico con otros a (lo que ella considera) las bondades de la nación: "Preguntemos, por ejemplo, ¿en qué otro lugar del mundo encontraríamos una política más preocupada por el respeto al otro, más atenta a los derechos de los ciudadanos (incluidas las mujeres y los extranjeros, a pesar de faltas y crímenes), más preocupada por la extrañeza individual, en el seno de una gran movilidad nacional?" (46-47; énfasis mío).

Los límites del cosmopolitismo de Kristeva salen a relucir de nuevo cuando sugiere - recordándonos la preferencia que muestra Ozick por Rut sobre Orpá- que las “ventajas 'abstractas' de un universalismo francés podrán resultar superiores a los beneficios 'concretos' del velo musulmán", implicando que el velo, a diferencia de la nación, es esencialmente un fetiche y por lo tanto incapaz, como tal, de funcionar como sano objeto transicional (47). ${ }^{15}$ Kristeva parece estar pensando en quienes llevan el velo cuando dice que "hay madres (así como 'madres

${ }^{15}$ Es cierto que Kristeva nota lo tenue que es la distinción entre fetiche y objeto transicional cuando acepta que el objeto transicional es "el fetiche indispensable de cualquier infante" (41). 
patrias') que impiden la creación del objeto transicional; hay niños incapaces de emplearlo" (41-42). Para Kristeva, estas mujeres que usan velo son algo parecido a lo que Orpá es para Ozick: atadas a sus ídolos, sus madres y sus madres patrias, capaces de cierta valentía en sus traslados pero ultimadamente incapaces de una transición adecuada y madura; representan lo que Kristeva llama la "melancolía" del nacionalismo (43).

Kristeva no se equivoca cuando ve posibilidades generativas en una concepción distinta de la nación francesa (47). ¿Por qué no otorgarle la misma posibilidad al velo musulmán? En su libro Women and Gender in Islam, Leila Ahmed (223-224) resalta las propiedades transicionales del velo en un contexto particular. Ahmed argumenta que para las mujeres musulmanas de Egipto, donde cada vez más profesionistas y universitarias usan el velo, este opera como objeto transicional, permitiéndoles a las mujeres con movilidad social desplazarse de los ambientes familiares de sus hogares rurales para "emerger socialmente a un mundo en que ambos sexos viven integrados", el cual "sigue siendo una realidad ajena e incómoda para muchos, tanto mujeres como hombres". Resulta irónico notar que, si es cierto que el velo puede funcionar como un sano objeto transicional, entonces la idea de Kristeva de que lo concreto del velo tiene que dar paso a la deseable abstracción del cosmopolitismo la colocaría precisamente en la posición de aquellas madres que ella critica, aquellas “madres (y aquellas 'matrias' y 'patrias') que impiden la creación del objeto transicional". ${ }^{16}$

\footnotetext{
${ }^{16}$ Ahmed estudia el uso del velo en Egipto, no en Francia, pero un argumento parecido hace en Francia la Federación de Consejos de Padres de Alumnos en Escuelas Públicas (Fédération des conseils de parents d'élèves des écoles publiques, o FCPE), la cual se opuso a la expulsión de más de setenta niñas que llevaban velo a sus escuelas de Lille y la región de París: "estas expulsiones llevan consigo 'el enorme inconveniente de confinar a estas jóvenes a su círculo familiar y de reducir cualquier posibilidad de emancipación"” (Migration News Sheet, noviembre 1994, 2). Kristeva nunca se pregunta por qué, igual que tantos otros, ella elige expresar su inquietud respecto al particularismo musulmán a través de las mujeres musulmanas. No sería una pregunta nueva, pues ya la hizo Fanon en A Dying Colonialism (originalmente
} 
Esta agradable ironía, sin embargo, no debería llevarnos a ignorar el hecho de que el problema con Kristeva no es sencillamente que por un lado ignore las propiedades transicionales del velo mientras que por otro logre ver las posibilidades transicionales de la nación. Si ese fuera el problema, un simple cambio de posición por su parte acerca del velo lo resolvería. ${ }^{17}$ Pero el verdadero problema es que Kristeva no involucra a Otros en sus deliberaciones sobre el proyecto, las metas y los instrumentos de un cosmopolitismo que ella valora demasiado como para arriesgarse a que figure en la conversación como pregunta en vez de como la respuesta. Y es que Kristeva llega a esta extraña posición porque no presta atención a lo que Judith Butler ("Kantians in Every Culture?", 18) llama la "difícil labor de traducción", un proyecto continuo de trabajo político que conlleva siempre una autointerrogación crítica y que se abre al riesgo de la transformación. Sin un compromiso con dicha labor, el cosmopolitismo de Kristeva ya sabe qué es y qué no es, con lo cual se arriesga a convertirse en otra forma de dominación, en especial cuando se enfrenta a un Otro que se resiste a asimilarse a él, un Otro que se niega a reeditar ante "nosotros" la admiración original de convertirse a la ciudadanía mundial (o francesa).

Cuando Kristeva sí invita a un intercambio con los "extranjeros, [que] somos todos (en nosotros y en relación a otros)", imagina que ello "ampliará y enriquecerá la idea francesa de nación" (Nations without Nationalism, 47). Pero este intercambio imaginario, en el cual Otros están allí para completar la idea

publicado en Francia en 1959 por François Maspéro bajo el título de L'An Cinq, de la Révolution Algérienne). Winnifred Woodhull aventura una respuesta, aunque sin pensar en Kristeva. Haciendo eco de Fanon, dice que "A ojos de muchos franceses, las niñas de ascendencia magrebí suelen ser estudiantes aplicadas y personas obedientes: en pocas palabras, el elemento más asimilable de la población inmigrante. El que ellas empiecen a defender su derecho a la 'diferencia', parecería que haría peligrar el proyecto entero de la integración” (Transfigurations of the Maghreb, 48).

${ }^{17}$ Agradezco a Pratap Mehta por este punto. 
francesa, tan solo hace patente la necesidad de un cosmopolitismo distinto, en el cual el cosmopolita arriesgue sus principios cosmopolitas (y nacionalistas) comprometiéndose con Otros en sus particularidades al mismo tiempo que defiende y descubre universalismos localizados como los derechos humanos o la dignidad de la persona. Las preguntas que Kristeva hace a los inmigrantes no reflejan ningún riesgo de este tipo: " $i$ Qué contribuye cada comunidad de inmigrantes al concepto laico de espíritu nacional como esprit general alcanzado por la iluminación francesa? ¿Reconocen estas comunidades dicho esprit general, o no?" (60).

Es verdad que comprometerse con el extranjero podría, siguiendo a Ozick y a Kristeva, motivar la renovación ética del cosmopolitismo democrático, pero la energía de dicha renovación no provendrá de que el extranjero afirme nuestras categorías existentes y perdone nuestras "faltas y crímenes" del pasado (Kristeva, Nations without Nationalism, 46). Más bien, la renovación del cosmopolitismo, el lugar y la fuente de su energía, vendrá del compromiso con extranjeros que parecen ser una amenaza pero con quienes la acción conjunta es sin embargo posible —quizá nada fácil, pero posible.

Duelo, pertenencia, agencia y pérdida: la lección de Rut para la política

El Libro de Rut puede inspirar un cosmopolitismo democrático. Ahora vuelvo a dicho libro a través de la noción psicoanalítica del objeto transicional, con el fin de explorar la experiencia de la pérdida y el duelo en los proyectos de transición y traducción. La elección de enfocarme en el objeto transicional se explica porque el tema aquí es la transición a un cosmopolitismo democrático por venir, y porque dicho instrumento es central tanto en la descripción que hace Kristeva de la inmigración 
como en la lectura que hace Ozick del Libro de Rut, en la cual Noemí es el objeto transicional que le permite a Rut trasladarse progresivamente de Moab a Israel (Ozick, "Ruth”, 227-228). Esto no quiere decir que yo considere al psicoanálisis un método universal; más bien me parece un paradigma cultural que explora las experiencias de compensación y pérdida en resonancia con ciertas comunidades y culturas, no solo individuos. Cierta imagen que apareció recientemente en el New York Times Book Review (5 de julio de 1995), que muestra un biberón con la bandera dentro y acompaña la reseña de The Next American Nation de Michael Lind, muestra claramente las conexiones simbólico-culturales entre el nacionalismo, la inmigración, el psicoanálisis y los objetos transicionales.

La escuela psicoanalítica de las relaciones objetales, que modela la separación y la autonomía a partir de la progresiva independencia del niño con respecto a su madre, enfatiza el papel de los objetos transicionales en el proceso de individuación. Yo me valgo de cierta versión de dicho modelo, pero también tomo distancia del excesivo énfasis en la relación originaria con la madre para afirmar la permanencia del problema de la separación, pues pienso que la separación y la transición no atañen solo a niños o a inmigrantes, sino a todos nosotros a lo largo de nuestras vidas. También busco evitar la trayectoria progresiva de las teorías del desarrollo, pues esta infantiliza a los inmigrantes, cuyas transiciones son parte de lo que está en juego aquí y contribuye a reafirmar la percepción por parte de los regímenes occidentales de que los regímenes de origen constituyen un "pasado que Occidente ya ha atravesado" y que puede ser abandonado sin pérdida (Visvanathan, "From the Annals of the Laboratory State", 41) (Las descripciones progresivas de Kristeva y de Ozick también podrían alimentar dichos prejuicios).

Eric Santner, quien en su análisis inspirado en Winnicott enfatiza la pérdida que ocasiona y acompaña a la individuación y 
la separación, argumenta que los objetos transicionales solo pueden fomentar una separación sana bajo ciertas condiciones (Stranded Objects, 19-26). Primero, que la separación no sea traumática, sino temporal. Segundo, que esto suceda en un ambiente sano y propicio para el juego con el objeto transicional. Tercero, que dicho juego tenga una dimensión intersubjetiva, es decir, que se dé ante un testigo cuyas ausencias temporales puedan ser soportadas. Si estas condiciones se cumplen, el espacio del juego objetal puede dar lugar a un duelo sano por la pérdida que la transición conlleva. Al jugar con el objeto transicional, el sujeto actúa su dolor y adquiere entonces la capacidad de separarse e individuarse, como en el juego del "fort-da" -que aleja al objeto para luego reencontrarlo- que describe Freud. Aquí no solo se lleva a cabo un duelo, también se adquiere un poder: el juego no solo le aporta al sujeto un sustituto (por la pérdida que lamenta) sino también una lección en relación a lo que Peter Sacks llama "el medio mismo y la práctica de la sustitución" (The English Elegy, 8). En el mejor de los casos, el sujeto aprende a ser agente ante la pérdida (y aun como resultado de la pérdida, si las condiciones para tal aprendizaje son propicias).

Si estas condiciones no se cumplen, ni sobrevendrá el duelo ni se adquirirá dicho poder. El sujeto hará del objeto un fetiche, y para negar su pérdida jugará con él furiosa e hiperbólicamente. Luego, el objeto perderá todo significado para el sujeto, que acabará por abandonarlo del todo, dejándolo varado. Evacuar el significado del objeto puede llevar a un "trauma de significación”, el cual deja al sujeto varado, silencioso, sin palabras, fuera del mundo del lenguaje, el juego y el duelo. Santner, quien enfatiza las tres dimensiones del juego con el objeto transicional -el duelo, el empoderamiento y la intersubjetividad - resume la idea de Winnicott con el siguiente aforismo: "El duelo sin solidaridad [es decir, el juego con el objeto transicional fuera de un campo intersubjetivo o sin una atestiguación 
intersubjetiva] es el principio de la locura" (Stranded Objects, 26-27).

¿De qué manera aplica esta descripción al Libro de Rut? Santner dice que la transición exitosa no depende de la naturaleza del objeto transicional mismo, sino del contexto en el cual este opera, con lo cual apunta al papel de las instituciones, la cultura, la comunidad y la política en los proyectos de transición y traducción, algo a lo que Kristeva no le presta la atención adecuada en su crítica al particularismo del inmigrante. Además, el lugar central que para Santner tienen el duelo, el empoderamiento y la intersubjetividad hace patente que Rut no dispone de ninguno de estos tres componentes de la transición exitosa. La separación entre Rut y Orpá (quien, según mi recuento, personifica a Moab) es traumática. No están presentes ni un sano espacio para el juego con el objeto transicional ni una atestiguación intersubjetiva, y tampoco la posibilidad de un duelo adecuado, pues Rut no obtiene sanción cultural, jurídica o psicológica para poder estar en duelo por Orpá-Moab. Para el caso, tampoco nosotros. Rut tomó la decisión correcta, en eso Ozick y Kristeva están de acuerdo. ¿Por qué hablar de duelo?

Ozick y Kristeva parecen asumir que al afirmar que la decisión de Rut fue correcta (y marginalizar a Orpá) afianzan su transición a Moab. Pero si Santner y Winnicott están en lo cierto, más bien hacen lo opuesto: insistir solamente en lo correcta que fue la decisión de Rut le quita (y nos quita) la posibilidad de entrar en duelo por Orpá-Moab y, sin un adecuado trabajo de duelo, se pone en peligro $-\mathrm{y}$ aun se subvierte, pero ciertamente no se afianza - su transición. El poder de Noemí como objeto transicional depende de que Rut pueda hacer un duelo adecuado por Orpá, y también de que establezca cierto tipo de relación continua (¿quizá compleja?) con ella. Depende, por lo menos, del reconocimiento de que Orpá (Moab) es parte de Rut. En términos de Ozick y Kristeva, podríamos decir que, si Rut 
llega a percibir la universalidad, ello siempre irá de la mano de cierta particularidad con la cual quizá entrará en tensión, pero de la cual Rut y su percepción desde luego se nutren.

De hecho, en oposición a Ozick y Kristeva, el Libro de Rut puede leerse como una fábula sobre el duelo incompleto, la transición fallida. A través del lente que nos ofrece Santner, la famosa lealtad de Rut a Noemí supera las interpretaciones idealistas y pragmáticas consideradas arriba. Ya no podrá señalar solamente la devoción desinteresada de una mujer virtuosa o su sentido práctico como inmigrante (esta última, posibilidad que yo misma he planteado junto a Fewell y Gunn, Compromising Redemption). Ahora también se hace posible que esta adhesión sea síntoma de la negación, por parte de Rut, de su pérdida de Orpá-Moab, signo de la primera etapa de Santner, en la cual la negación de la pérdida lleva a un apego frenético que convierte al objeto transicional en fetiche.

Asimismo, tampoco el silencio final de Rut podrá indicar tan solo una absorción exitosa y completa. Otra posibilidad se nos impone: que el silencio señale la segunda etapa de Santner, en la cual el sujeto sufre de un "trauma de significación". En el caso de Rut, dicho trauma se produce cuando se separa de OrpáMoab y de manera concomitante pierde cualquier relación significativa con Noemí, su madre adoptiva (transicional). El que Noemí adopte a Obed y sustituya a Rut simboliza esta segunda pérdida, la cual sin embargo se anuncia desde mucho antes, por ejemplo cuando Noemí no presenta y ni siquiera menciona a Rut ante las mujeres que la reciben en Belén.

Estos dos momentos de la historia de Rut marcan dos tiempos típicamente presentes en las dinámicas de inmigración modeladas por las democracias multiculturales contemporáneas. Uno, el del asimilacionismo furioso e hiperbólico (o cosmopolitismo asimilativo), que desmiente cualquier conexión con la madre patria. Dos, un rechazo de la transición, caracterizado por la retirada hacia el enclave separatista o nacionalista, que 
deja al inmigrante varado tanto en el país receptor como en relación a la patria perdida. Santner y Winnicott conciben estos dos momentos a partir de la teoría del desarrollo, pero de hecho aparecen simultáneamente en los inmigrantes y en sus regímenes receptores.

Esta dicotomía entre absorción y enclavismo es generada por los esfuerzos de recuperar la extranjería para proyectos nacionales (o nacionalistas). ¿Habrá manera de escapar a este dilema? Nuestro análisis sugiere dos direcciones: primero, es necesario que respondamos constructivamente a las invocaciones de los privilegios del anfitrión sobre el huésped que hoy en día resultan tan comunes (Kristeva, Nations without Nationalism, 60). En Estados Unidos, dichas invocaciones se manifiestan en fenómenos como el del movimiento "solo inglés", el de colocar al inmigrante como chivo expiatorio por el fracaso de la economía capitalista nacional e internacional para reproducir el sueño americano, el de culpar a los inmigrantes y a las minorías étnicas de la fragmentación de la alta cultura (lo cual resulta perverso en un momento en que los poderes homogeneizantes de la cultura popular estadounidense están en su apogeo) o el de identificar el enclavismo con los inmigrantes y las minorías étnicas en un momento en que la propensión a retirarse de los servicios públicos y la cultura pública es notoria no entre inmigrantes, sino entre los ricos.

Como respuesta a todo esto, nos corresponde proporcionar espacios de los que Rut en su momento no dispuso, espacios que permitan, por decirlo así, jugar con los objetos transicionales. Pero no debe confundirnos el término "juego": se trata de espacios que den lugar a un serio trabajo y negociación políticos, en los cuales se pueda comenzar el trabajo del duelo mientras se atienden otras necesidades de la convivencia. Y según nuestra propuesta, el duelo, por cierto, no solo les incumbe a los nuevos inmigrantes. Las transiciones y expansiones democráticas exitosas dependen de la voluntad tanto de la población receptora 
como de los inmigrantes de arriesgarse a la transformación mutua, a comprometerse con su anhelo de casa y también atenuarlo, en aras del otro y de su vida política conjunta. Tales acciones en concierto pueden surgir a través de asociaciones secundarias cuyos miembros no tienen que ser ciudadanos, aunque también ciudadanos participen en ellas: los grupos de barrio, la política que hacen las juntas de escuelas locales, organizaciones de defensa de los inmigrantes como el Centro de Derechos Laborales (Workplace Project) de Long Island (Gordon, "We Make the Road by Walking") y aun aquellas conocidas organizaciones de asistencia mutua entre inmigrantes, que supuestamente se retiran de lo público, pueden funcionar como espacios de participación democrática absorbente y transformativa de solidaridad y de ciudadanía de facto (aunque no de jure) (PerezBustillo, "What Happens When", 201).

Estas asociaciones secundarias deben ir de la mano con una educación que enseñe a los residentes a ser ciudadanos de un mundo cuya diversidad se reproduce dentro de las fronteras de la nación, adquirir segundas y hasta terceras lenguas, apreciar sus propias culturas y órdenes políticos como parte de una red más amplia de posibilidades democráticas, ver en dichos órdenes plataformas desde las cuales formar coaliciones subnacionales e internacionales y percibir sus instituciones democráticas como instituciones en formación y susceptibles a enmiendas que pueden ser resultado de la participación de inmigrantes (y aun de "extranjeros") en las prácticas y los movimientos democráticos a niveles subnacionales, nacionales e internacionales. Estados Unidos tiene una larga historia de sufragio de extranjeros ("finalmente desbaratada por el nacionalismo xenófobo alrededor de la Primera Guerra Mundial") en la cual la participación democrática se vincula no a la condición jurídica de ciudadano sino al hecho de ser residente (Raskin, "Legal Aliens, Local Citizens", 1397). Hoy en día, varias ciudades permiten que no ciudadanos voten en elecciones locales, de juntas de es- 
cuela (Chicago y Nueva York) o municipales (varias localidades de Maryland, como Takoma Park) (Raskin, "Legal Aliens, Local Citizens", 1429-1430). ${ }^{18}$

Una segunda dirección sugerida por este análisis apunta al nivel transnacional en vez de al subnacional, pero también es asociativa y afectiva. El vínculo fraterno que se quiebra entre Rut y Orpá recuerda al movimiento de las ciudades hermanas, el cual en cierta manera ejemplifica y podría ayudar a construir un futuro cosmopolitismo democrático. Por lo general, las ciudades hermanas, que son centros afectivos de un transnacionalismo localizado e institucional, se fundan a partir de energías e iniciativas cívicas. Dicho transnacionalismo las convierte en un complemento importante y potencialmente energizante para las solidaridades subnacionales arriba mencionadas. ${ }^{19}$ Además, como las ciudades hermanas establecen relaciones que no se limitan a "llevar a cabo un solo proyecto", se vuelven un complemento importante para formas de solidaridad local e internacional más temporales y centradas en temas específicos, las cuales funcionan con coaliciones (Zelinsky, "The Twinning of the World", 1). Pero sobre todo, las ciudades hermanas interrumpen proyectos de (re)nacionalización mediante la generación de prácticas de ciudadanía afectiva que desbordan las fronteras del estado (y aun violan la política externa del estado, Chilsen

${ }^{18}$ Sin embargo, también es preciso notar que la residencia puede resultar un requerimiento restrictivo en vez de permisivo. Otras ciudades, como Long Island, impiden que los inmigrantes ingresen a las escuelas públicas pidiendo estrictas pruebas de residencia (Carvajal, "Immigrants Fight", B4).

${ }^{19}$ El siguiente caso ilustra las conexiones — potencialmente empoderadoras aunque también controversiales - forjadas por coaliciones de grupos sub- y transnacionales, y también contradice la impresión de que las ciudades hermanas son asociaciones benignas y sin importancia. En 1988, el Lion's Club International de Taipei donó 10,000 libros en chino a la biblioteca pública de Monterey Park, con la intención de que dicho obsequio "fortaleciera la cercanía que sentían con la ciudad hermana, que muchos empezaban a llamar 'Little Taipei'”. Para el alcalde Barry Hatch, dicho obsequio era un asalto a los valores estadounidenses y peleó por rechazarlo; sin embargo, finalmente perdió ante una coalición de grupos cívicos locales y líderes de la comunidad china en Estados Unidos (Crawford, Hold Your Tongue, 1-3). 
y Rampton, Friends in Deed). Juntas, asociaciones subnacionales y transnacionales llevan a cabo una práctica cosmopolita. Proporcionan espacios de contrapeso a la política nacional(ista), así como lugares donde pueden desarrollarse y expresarse el duelo, el empoderamiento, la solidaridad y la agencia.

Una narración distinta del Libro de Rut revela que no es solo una fábula sobre la fundación y la inmigración, sino también una parábola sobre el duelo y la pertenencia, lo cual resulta apropiado. El libro muestra las condiciones institucionales y culturales que permiten un adecuado trabajo del duelo y hace patente la importancia de que espacios intersubjetivos, acciones en concierto, solidaridades múltiples, poderes cívicos y conexiones (siempre cuestionadas) con el pasado funcionen como agentes significativos y empoderados. Puesto que Noemí dispone en Belén de dichos espacios, acciones, poderes y conexiones, ella recupera su plenitud y su agencia. La situación de Rut es distinta, pues Belén coloca a Rut y a Noemí en posiciones asimétricas con respecto a sus pérdidas. La comunidad de mujeres recibe a Noemí con apoyo y simpatía, atestigua su cambio de nombre a Mara como parte de un duelo ritual (aunque nunca la llaman por dicho nombre) y ella adquiere poder como agente.

Dice Santner que "la constitución (y reconstitución) homeopática del self no sucede en un vacío, sino siempre en un contexto social específico" (Stranded Objects, 24). A Rut no se le otorgan dichos recursos ni dicho contexto, pues sus pérdidas no se perciben como tales y sus conexiones transnacionales con Orpá-Moab (posible sitio alternativo de apoyo y poder) se cortan de tajo. A Rut se le prohíbe el duelo por Orpá, como a Antígona por Polinices, en aras de la estabilidad e identidad del régimen. Así, el duelo de Rut, como el de Antígona, se vuelve interminable, melancólico. Sus pérdidas estorban al propósito que tiene la comunidad de verse reforzada por ella y a pesar de ella. La marca de la reinserción de Noemí a su comunidad es que ocupa la posición de Rut como madre de Obed, hecho singular que 
sugiere que esta comunidad se ve reforzada - y la monarquía de David estabilizada - no solo por el inspirador ejemplo de Rut, sino también, y al mismo tiempo, por su marginalización.

Las lecciones del Libro de Rut van mucho más allá del asimilacionismo de Ozick o del cosmopolitismo de Kristeva. Este gran cuento corto nos llama a avanzar hacia un cosmopolitismo democrático que busque afianzar, tanto para los inmigrantes como para las poblaciones receptoras, aquellas condiciones culturales, institucionales, éticas y políticas que propicien un adecuado trabajo del duelo $-\mathrm{y}$ de la vida — en conjunto.

\section{REFERENCIAS}

Biblia Hebrea, Moisés Katznelson, Sinaí, Tel-Aviv, 1996.

Ahmed, Leila, Women and Gender in Islam, New Haven, Yale University Press, 1992.

BORJas, George, Friends or Strangers: The Impact of Immigrants on the U.S. Economy, New York, Basic Books, 1990.

BrubaKer, Rogers, Citizenship and Nationhood in France and Germany, Cambridge, Harvard University Press, 1992.

ButLer, Judith, "Kantians in Every Culture?", Boston Review, 18 (oct.-nov. 1994).

Carvajal, Doreen, "Immigrants Fight Residency Rules Blocking Children in L.I. Schools", New York Times, 7 august 1995, A1, B4.

Chilsen, Liz y Sheldon Rampton, Friends in Deed:The Story of U.S. Nicaraguan Sister Cities, Madison, Wisconsin Coordinating Council on Nicaragua, 1988.

Crawford, James, Hold Your Tongue: Biligualism and the Politics of "English-only", Binghamton, Addison-Wesley, 1992.

DerridA, Jacques, Glas, Lincoln, University of Nebraska Press, 1986.

FAnon, Frantz, A Dying Colonialism, trad. Haakon Chevalier, New York, Grove Press, 1965. 
Fewell, Dana y David Gunn, Compromising Redemption: Relating Characters in the Book of Ruth, Louisville, Westminster / John Knox Press, 1990.

GoRdon, Jennifer, "We Make the Road by Walking: Immigrant Workers, the Workplace Project and the Struggle for Social Change", Harvard Civil Rights-Civil Liberties Law Review 30, 1995, 407450.

Hollifield, James, Immigrants, Markets and States: The Political Economy of Postwar Europe, Cambridge, Harvard University Press, 1992.

Honig, Bonnie, Democracy and the Foreigner, Princeton, Princeton University Press, 2001.

HuRst-W ARHAFt, Gail, Dangerous Voices: Women's Laments in Greek Literature, New York, Routledge, 1992.

Ignatiev, Noel, How the Irish Became White, New York, Routledge, 1995.

IRIGARAY, Luce, Speculum of the Other Woman, Ithaca, Cornell University Press, 1985.

Kaplan, Rosa Felsenburg, "The Noah Syndrome", en On Being a Jewish Feminist, Susanna Heschel (ed.), New York, Schocken, 1983.

__, "The Noah Syndrome", en Reading Ruth: Contemporary Women Reclaim a Sacred History, Judith A. Kates y Gail Twersky Reimer (eds.), New York, Ballantine, 1994.

Kates, Judith A., "Women at the Center: Ruth and Shavuoth", en Reading Ruth: Contemporary Women Reclaim a Sacred History, Judith A. Kates y Gail Twersky (eds.), Reimer, New York, Ballantine, 1994.

KRISTEVA, Julia, Extranjeros para nosotros mismos, trad. Xavier Gispert, Barcelona, Plaza y Janés, 1991.

—_, Nations without Nationalism, trad. Leon S. Roudiez, New York, Columbia University Press, 1993.

Labovitz, Priscilla, "Immigration-Just the Facts", The New York Times, 25 march 1996, op. ed. 
Morrison, Toni, "On the Backs of Blacks", en Arguing Immigration, Nicolaus Mills (ed.), New York, Simon \& Schuster, 1994, 97-100.

Moruzzi, Norma, "A Problem with Headscarves: Contemporary Complexities of Political and Social Identity", Political Theory, 22, 653-672.

Ozick, Cynthia, "Ruth", en Reading Ruth: Contemporary Women Reclaim a Sacred Story, Judith A. Kates y Gail Twersky Reimer (eds.), New York, Ballantine, 1994, 211-232.

Perez-Bustillo, Camilo, "What Happens When English Only Comes to Town? A Case Study of Lowell, Massachussetts", en Language Loyalties: A Sourcebook on the Official English Controversy, James Crawford (eds.), Chicago, University of Chicago Press, 1992, 194-201.

Portes, Alejandro y Ruben G. Rumbaut, Immigrant America: A portrait, Berkeley, University of California Press, 1990.

Raskin, Jamin B., "Legal Aliens, Local Citizens: The Historical, Constitutional and Theoretical Meanings of Alien Suffrage", University of Pennsylvania Law Review, 141, 1391-1469.

ReImer, Gail Twersky, "Her Mother's House", en Reading Ruth: Contemporary Women Reclaim a Sacred Story, Judith A. Kates y Gail Twersky Reimer (eds.), New York, Ballantine, 1994, $97-$ 106.

Rousseau, Jean-Jacques, "On the Social Contract", en The Basic Political Writings, trad. Donald A. Cress, Indianapolis, Hackett, 1988, 141-227.

SACKs, Peter, The English Elegy: Studies in Genre from Spenser to Yeats, Baltimore, Johns Hopkins University Press, 1985.

SANTNER, Eric L., Stranded Objects: Mourning, Memory and Film in Postwar Germany, Ithaca, Cornell University Press, 1990.

SAsson, Jack M., Ruth: A New Translation with a Philological Commentary and Formalist-Folklorist Interpretation, Sheffield, JSOT, 1989.

Ungar, Sanford, Fresh Blood: The New American Immigrants, New York, Simon \& Schuster, 1995. 
Visvanathan, Shiv, "From the Annals of the Laboratory State", Alternatives: A Journal of World Policy, 1987, 12, 37-59.

Wolfe, Alan, "The Return of the Melting Pot", The New Republic, 31 december 1990, 27-34.

Woodhull, Winifred, Transfigurations of the Maghreb: Feminism, Decolonization and Literatures, Minneapolis, University of Minnesota Press, 1993.

ZeLINSKy, Wilbur, "The Twinning of the World: Sister Cities in Geographical and Historical Perspective", Annals of the Association of American Geographers, 81: 1, 1991, 1-31. 